\title{
Demystifying consumer digital cocreated value: social presence theory-informed framework and propositions
}

Article

Accepted Version

Hollebeek, L. D., Clark, M. K. and Macky, K. (2021)

Demystifying consumer digital cocreated value: social presence theory-informed framework and propositions.

Recherche et Applications en Marketing (English Edition), 36 (4). pp. 24-42. ISSN 2051-5707 doi:

https://doi.org/10.1177/2051570720961986 Available at https://centaur.reading.ac.uk/95459/

It is advisable to refer to the publisher's version if you intend to cite from the work. See Guidance on citing.

To link to this article DOI: http://dx.doi.org/10.1177/2051570720961986

Publisher: Sage

All outputs in CentAUR are protected by Intellectual Property Rights law, including copyright law. Copyright and IPR is retained by the creators or other copyright holders. Terms and conditions for use of this material are defined in the End User Agreement. 


\section{CentAUR}

Central Archive at the University of Reading

Reading's research outputs online 


\title{
Demystifying Consumer Digital Cocreated Value:
}

\section{Social Presence Theory-Informed Framework and Propositions}

\section{Please cite as:}

Hollebeek, L., Clark, M. \& Macky, K. (2020), Demystifying Consumer Digital Cocreated Value: Social Presence Theory-Informed Framework and Propositions, Recherche et Applications en Marketing, Forthcoming, DOI: 10.1177/2051570720961986.

\begin{abstract}
While cocreation research proliferates, existing studies fail to isolate its manifestation through digital (vs. non-digital) platforms. Moreover, extant research predominantly explores the cocreation process (vs. its outcome of cocreated value), which therefore merits further scrutiny, particularly in the digital context. Based on these gaps, we explore consumer digital cocreated value (CDCV), which reflects the consumer-perceived value that arises by interacting, collaborating, or communicating with or through digital platforms (touch-points). We classify digital platforms as (i) human-to-human platforms (H2HPs; e.g. social media), and (ii) human-to-machine platforms (H2MPs), which comprise the sub-types of (a) robotic process automation-based platforms (e.g. call centers), and (b) machine/deep learning-based platforms (e.g. service robots). We next compose a social presence theory-informed framework that explores the effect of perceived platform intimacy and immediacy on CDCV for our proposed platforms. We formalize the framework's associations by developing a set of Propositions, and conclude by discussing important implications that arise from this research.
\end{abstract}

Keywords: Consumer digital cocreated value (CDCV), digital platform, social presence theory, artificial intelligence. 


\section{Introduction}

In the last two decades, (value) cocreation has seen growing scholarly and practitioner interest (Ranjan and Read, 2016). Indeed, "value [co]creation ... can be regarded as the raison d'être of collaborative ... relationships" (Anderson, 1995, p. 349). On account of its value-creating capacity, organizations across a range of sectors, including hospitality, education, fast food, and professional services are increasingly adopting cocreation as a key performance indicator (Merz et al., 2018; Grissemann and Stokburger-Sauer, 2012). For example, the MyStarbucks digital platform is designed to process orders, personalize client activities, and offer support, thereby cocreating value with customers (Fournier, 2019).

In parallel, academic cocreation research is proliferating, including from an S-D logic perspective (Vargo and Lusch, 2016; Leclercq et al., 2016). Given its interactive core, cocreation can emerge through different (e.g. face-to-face/digital) platforms (Keeling et al., 2019; Banker et al., 2011). Platforms are "physical or virtual touch-points designed to provide structural support for ...exchange" (Hollebeek, 2019, p. 89), which facilitate value cocreation (Ramaswamy and Ozcan, 2016). However, despite the significant strides made in cocreation research, insight into cocreation manifested through digital platforms lags behind, generating an important research gap (Novani and Kijima, 2012; Füller, 2010). Digital platforms are computerized, technology-enabled touch-points that are conducive to cocreation (Kannan and Li, 2017; Vanhouette, 2016; Breidbach et al., 2014), including social media- (e.g. Facebook), sharing economy- (e.g. Uber), and artificial intelligence-based platforms (e.g. Nao robot), to name a few. In particular, existing digital cocreation research has tended to address a single, siloed or isolated digital context (e.g. social media; He and Wan, 2015). Thus, despite technology's ever-growing importance (Drucker, 2011), studies that explore cocreation's dynamics across different digital platforms remain few and far between, as therefore addressed in this paper.

Moreover, though cocreation research is flourishing (Balaji and Roy, 2017), prior studies devote limited attention to cocreation's value-based outcome of cocreated value, revealing a second research gap. That is, while cocreation centers on actors' interactive value creation process (Dampérat et al., 2019), cocreated value emerges as the perceived value-based outcome (i.e. interactively-generated value) of this process (Busser and Shulga, 2018; Black and Gallan, 2015). Given the relative paucity of cocreated value research to date, we address this concept by focusing on its technology-enabled sub-set of consumer-perceived digital cocreated value (CDCV; GyrdJones and Kornum, 2013), in line with our first research gap. Though CDCV reflects the perceived value created by interacting with technology-enabled touch-points, the digital platform's role in 
fostering cocreated value remains nebulous, thus warranting further exploration. Similar to Kannan and Li's (2017) investigation of digital marketing as a marketing sub-set, this conceptual paper therefore examines $\mathrm{CDCV}$ as a sub-set of cocreated value (i.e. that value cocreated via digital platforms). That is, unlike broader cocreated value that may transpire through (non-)digital platforms, digital cocreated value requires (a) digital platform(s) to emerge.

Given our view of digital platforms as technological touch-points (Breidbach et al., 2014), we do not focus on the related notion of platform business, which captures (online) companies' business model that intermediates consumer/supplier exchange (e.g. AirBnB; Täuscher and Laudien, 2017). While platform businesses deploy specific (digital) platforms (e.g. Uber's app; Smedlund, 2012), our focus is limited to consumer interactions with these touch-points and their respective effects on digital cocreated value (Tu and Zhang, 2013; Breidbach et al., 2014).

As digital platforms exist in a range of shapes and forms, we develop a digital platform typology, and assess each platform's capacity to yield digital cocreated value. Though the existing literature offers several related classifications, none of these specifically focus on a platform's technological characteristics and their implications for digital cocreated value, as undertaken here. For example, while Wünderlich et al.'s (2013) four-partite typology classifies smart interactive services based on low/high user- and provider activity, their focus on human (i.e. user/provider) engagement, like Füller (2010), precludes a direct assessment of the role of specific digital platform characteristics in driving cocreated value from these services. Moreover, Bolton and Saxena-Iyer (2009) categorize the extent to which services are technology-enabled/delivered (low/high) under low/high levels of customer participation, respectively, yielding a four-partite service interactivity typology. While the former dimension indeed addresses platform-related technology, it assesses the extent of deployed technology, rather than its particular characteristics, like our classification. Drawing on social presence theory, we also develop a framework that explores our platforms' respective effects on consumer digital cocreated value, followed by the development of a set of Propositions that summarize the framework's associations.

This conceptual paper offers two main contributions. First, following an extensive review, we develop a typology of digital platforms. Theoretical typologies are classifications used to understand the categories characterizing specific phenomena of interest (Hambrick, 1984). Our digital platform typology comprises: (i) human-to-human platforms (e.g. mobile apps), and (ii) human-to-machine platforms, which contain the sub-categories of (a) robotic process automationbased platforms (e.g. call centers), and (b) machine/deep learning-based platforms (e.g. service robots; Pradeep et al., 2019). We envisage unique CDCV dynamics for these typological categories, as discussed further below, thus offering an important springboard for future empirical research. 
Second, we develop a social presence theory-informed framework of CDCV, responding to literature-based calls for a rigorous cocreated value framework (Black and Gallan, 2015; Huber et al., 2017). Examining the capacity of interactive platforms to transmit social cues, social presence theory proposes the existence of cross-platform differences in terms of their capacity to foster userperceived intimacy and immediacy (Short et al., 1976), thus differentially affecting CDCV. While intimacy and immediacy are optimized in face-to-face interactions, we focus on their dynamics when using different digital platforms (Van Doorn et al., 2017). We adopt a social presence theory perspective, given its focus on identifying trans-platform differences and their respective effects on CDCV, thus making an important contribution. Though S-D logic represents cocreation's leading theoretical perspective (e.g. Vargo and Lusch, 2016), its highly abstract, metatheoretical nature precludes it from pinpointing cross-digital platform hallmarks and their implications for CDCV. We therefore model CDCV in a social presence theory-informed framework, following MacInnis' (2011, p. 141) position that knowledge advances "by conceptualizing [a concept's] relationship to other concepts, often in a nomological network." Relatedly, we develop a set of Propositions that formalize the framework's associations for our identified digital platforms. Collectively, our analyses offer a catalyst for future empirical CDCV research and managerial insight into CDCV.

The next sections unfold as follows. We proceed by reviewing cocreation/cocreated value literature, which offer an important foundation for our analyses. We then develop a digital platform typology, followed by the composition of a social presence theory-informed framework of CDCV. Based on the framework, we derive a set of Propositions, followed by an overview of this study's implications, limitations, and avenues for further research.

\section{Literature review}

\section{Cocreation research}

Most published research addresses the cocreation process, rather than the value-based result of this process (Black and Gallan, 2015), as outlined. Thus, while cocreation unfolds as a sequence of steps (Buonincontri et al., 2017; Alves et al., 2018; Vega-Vazquez et al., 2013), cocreated value reflects the level of actor (e.g. consumer)-perceived value that arises from these events (Huber et al., 2017; Mahr et al., 2014). Given the relative scarcity of cocreated value research, we next review cocreation literature, followed by a review of published work on cocreated value. Drawing on these analyses, we conceptualize CDCV at the end of the next section.

With its foundations (e.g. coproduction) emerging in the mid/late 1990s (Normann and Ramírez, 1994; McColl-Kennedy et al., 2012), the cocreation concept was first coined in the early 
2000s (Nicod and Llosa, 2018; Dong and Sivakumar, 2017). For example, Prahalad and Ramaswamy's (2004) cocreation experience proffers the customer's experience of the offering (vs. the offering itself) as a core foundation for perceived value, akin to value-in-use (vs. value-inexchange; $\mathrm{Ng}$ et al., 2011; Humphreys and Grayson, 2008). Here, perceived value implies the consumer's internal offering-related cost/benefit trade-off (Zeithaml, 1988; Woodruff, 1997).

In parallel, Vargo and Lusch (2004) incorporated cocreation in their emerging S-D logic perspective. These authors view actors as active (vs. passive) contributors to their own value creation (Mahr et al., 2014; Schau et al., 2009). When such value creation transpires with, through, or for others (e.g. through online community interactions), it is construed as cocreation. Prahalad and Ramaswamy (2000, p. 80) concur: "Increasingly, [consumers] want to shape [i.e. cocreate] ...experiences themselves [including] with experts or other customers."

Though pioneering cocreation research was not linked to S-D logic per se, over time the concept has become increasingly linked to this perspective (Dahl et al., 2019; Hollebeek et al., 2020b). For example, cocreation does not feature in Vargo and Lusch's (2004) original S-D logic Premises. However, four years later the authors incorporate it in FP6, which states: "The customer is always a cocreator of value" (Vargo and Lusch, 2008, p. 7). Yet, cocreation still lacks a formal definition in these papers (Hollebeek et al., 2020b). In 2016, Vargo and Lusch however define cocreation as "the actions of multiple actors, often unaware of each other, that contribute to each other's wellbeing" (p. 8). They also revise FP6 (p. 8) to: "Value is cocreated by multiple actors, always including the beneficiary," evidencing cocreation's progressively central role in S-D logic. While some authors limit cocreation's scope to human-to-human interactions (Grönroos and Voima, 2013), others - including those taking an S-D logic perspective - extend it to incorporate other (e.g. human-to-machine) interactive forms (Caic et al., 2018; Brodie et al., 2016), as adopted here.

Cocreation comprises two components: co and creation. First, as a testament to its inherent interactivity, its prefix "co" (with) denotes the concept's reliance on the presence of or interdependencies with other actors, with whom the focal actor interacts, collaborates, or communicates (Lusch et al., 2007; Brodie et al., 2013; Chen et al., 2018). Cocreation is therefore highly context-specific, akin to value-in-context (Chandler and Vargo, 2011). Second, its creation part reveals the concept's proactive, action-based or “doing” nature (McColl-Kennedy et al., 2012; Cova et al., 2011; Delpechitre et al., 2018; Oertzen et al., 2018).

Unlike cocreation, which reflects the process of actors' interactive value creation, codestruction reflects value attrition through interactions (Heidenreich et al., 2015; Smith, 2013; 
Zhang et al., 2018). In line with Bowden et al. (2017), consumer-perceived cocreation/destruction levels can fluctuate in or across interactions. Thus, though one interaction can be seen as valueadding, another may erode perceived value (e.g. service failure; Plé and Chumpitaz Cáceres, 2010). Moreover, while particular interaction-related aspects may cocreate value (e.g. rapid firm response times), others can be value-detracting (e.g. presence of disliked actors in the servicescape; Clark et al., 2020). Akin to Zeithaml's (1988) perceived value trade-off, net cocreation arises as the balance of consumer-perceived cocreation/destruction in an interaction, collaboration, or communication.

Not only interaction participants affect actor-perceived cocreation, but other networked actors may also exert indirect effects, whether consciously or not (Leclercq et al., 2016; Ranjan and Read, 2016). For example, a robotic waiter's actions are not only affected by present-, but also by prior customer needs and wants that have helped "train" it (Bèzes, 2019; Hollebeek et al., 2020b). Cocreation therefore incorporates individual actor- and more systemic factors that mutually affect one another (Edvardsson et al., 2011; McColl-Kennedy et al., 2012). In this paper, we focus on consumer-perceived cocreated value (Busser and Shulga, 2018; Witell et al., 2011). Lusch et al. (2007) posit: "Value can only be determined by the user [i.e. consumer] in the consumption process," warranting consumer cocreated value's importance. Key actors with whom consumers may cocreate value include firms/brands, service staff, and fellow consumers (Hult et al., 2011; Clark et al., 2020).

\section{Cocreated value research}

Despite the two-decade history of cocreation research, insight into its value-based outcome of cocreated value lags behind (Black and Gallan, 2015; Go Jefferies et al., 2019). Like cocreation, cocreated value has its origins both in (e.g. Cova and Salle, 2008; Cabiddu et al., 2013) and outside of S-D logic (e.g. Prahalad and Krishnan, 2008). Consequently, definitional consensus is lacking, and some authors leave the concept undefined (e.g. Go Jefferies et al., 2019). Busser and Shulga (2018, p. 69) define cocreated value as a consumer's "personal appraisal of the meaningfulness of a service based on what is contributed and what is realized through collaboration." We agree regarding cocreated value's highly subjective, collaborative nature (Vargo and Lusch, 2016; Lee et al., 2012), to which we add the key enabling role of interactivity or communication (Verma et al., 2012; Gummesson and Mele, 2010), as outlined. We also concur regarding consumers' internal cost/benefit trade-off in appraising their cocreated value (Zeithaml, 1988), which can be positive (i.e. cocreated value) or negative (i.e. codestroyed value; Heidenreich et al., 2015; Caic et al., 2018).

Black and Gallan (2015, p. 2) view cocreated value as consumer-perceived value through synergized user "contributions, network support, and macro-environmental conditions." We agree 
that consumer cocreated value is influenced by external, largely uncontrollable ecosystem (e.g. market) forces that extend beyond the interaction participants alone, as outlined for cocreation. That is, cocreated value relies on some micro-, meso-, or macro-level actor ensemble (vs. a single actor), whether through actual interactions or actor interdependencies (Akaka et al., 2012). Here, actors may have differing goals or agendas, thus potentially complicating the attainment of mutual cocreated value (Hult et al., 2011; Clark et al., 2020). For example, while one actor's goal fulfilment may cocreate value for her (e.g. by winning a contest), it can detract value for another (Huber et al., 2017; Bailey et al., 2018). This example also illustrates the importance of actor goals in fostering cocreated value (Go Jefferies et al., 2019). Overall, Busser and Shulga's (2018) and Black and Gallan's (2015) definitions concur in terms of cocreated value's inherent subjectivelydetermined importance to the consumer.

Though we distinguish cocreation and cocreated value, we observe a degree of semantic confusion that surrounds both concepts. That is, as some cocreation authors in fact refer to cocreated value, we also consider their conceptualizations in defining CDCV. For example, McColl-Kennedy et al. (2012, p. 370) view customer value cocreation as the "benefit realized from integration of resources through activities and interactions with collaborators in the [actor's] service network." Given this definition's benefit (i.e. value-based outcome) focus, the authors' focal concept actually reveals cocreated value (vs. cocreation). Similarly, Ng et al. (2011, p. 14) define value cocreation as "[value] that is jointly ...created between the customer and the firm for benefit," thus also referring to the value-based outcome of cocreative processes. Likewise, Hollebeek et al. (2019, p. 168) define customer cocreation as a client's "perceived value arising from interactive, joint, or collaborative brand-related activities for/with stakeholders."

In sum, our review reveals consumer cocreated value's highly subjective, perceived valuebased nature that emerges from consumer interactions, collaboration, or communication with other service system actors, including firms/brands, employees, and fellow consumers (Vargo and Lusch, 2016; Ng et al., 2011; Ranjan and Read, 2016; Verma et al., 2012). Given our focus on digital cocreated value, our scope is limited to value cocreated through digital platforms (Breidbach et al., 2014), as discussed further in the next section. Based on our review, we define CDCV as the consumer-perceived value that arises by interacting, collaborating, or communicating with or through digital platforms (touch-points).

Recognizing CDCV's differing valence, its scope includes positive perceived (i.e. cocreated) and negative perceived (i.e. codestroyed) value (Echeverri and Skålén, 2011; Gebauer et al., 2013; Daunt and Harris, 2017). Thus, unlike CDCV, which transpires as a consumer's positive perceived 
value from an interaction, digital codestroyed value occurs when such value is negative (e.g. through cyber-bullying; Kowalski et al., 2012). We next elaborate on the digital platform aspect of our CDCV definition by proposing a digital platform typology.

\section{Conceptual development}

\section{Digital platform typology}

Digital platforms, which are technology-enabled or "virtual touch-points designed to provide structural support for ...exchange" (Hollebeek, 2019, p. 89), are important interactionenabling and value-cocreating conduits (Ramaswamy and Ozcan, 2018; Breidbach et al., 2014), as outlined. While some platforms facilitate face-to-face interactions (e.g. meetings), our analyses are limited to digital platforms that enable consumer interactions, collaboration, or communication through computerized, technology-enabled touch-points (Ramaswamy and Ozcan, 2016; Kannan and Li, 2017; Troisi et al., 2018), as also discussed. Because digital platforms yield cocreated value in different ways, we develop a digital platform typology that comprises human-to-human- and human-to-machine platforms, as detailed below.

Human-to-human platforms (H2HPs) are computerized, technology-enabled touch-points that mediate or intercede human-to-human interactions, collaboration, or communication. These platforms offer an interface that acts as the go-between in connecting individuals (e.g. mobile apps; Pirrone et al., 2012; Breidbach and Maglio, 2016), where one's interaction partner may or may not be known personally (Brzozowski et al., 2008). H2HPs' relational, communicational focus can facilitate the development of strong or weak ties (e.g. through one-on-one vs. many-to-many interactions; Granovetter, 1983). Given these platforms' interaction-mediating role, H2HP users may present themselves based on their true identity or construe an alternate character (e.g. through avatars, catfishing; Lovelock, 2017).

Software-based H2HPs differ from the hardware (devices) on which they are run, which are known as platform archetypes (Hollebeek et al., 2020a). H2HP examples include social media, online communities, websites, mobile apps, social gaming, instant messaging, and online telephony platforms (Raïes and Gavard-Perret, 2011; Kohler et al., 2011; Bernal-Merino, 2016; He and Yan, 2015; Algharabat, 2018).

Human-to-machine platforms (H2MPs) are computerized touch-points that connect with users (e.g. service robots; Wirtz et al., 2018; Van Doorn et al., 2017). That is, H2MP-based technology is the consumer's interaction partner, revealing these platforms' interaction-enabling role, where interactions can be user- or platform-initiated. While these platforms can fulfil a relational role (e.g. social robots bonding with users), they - unlike H2HPs - are not designed to 
facilitate human-to-human interactions (Marin et al., 2009). Instead, H2MPs execute particular tasks for (i.e. offer service to) consumers by enhancing their efficiency, effectiveness, or performance through artificial intelligence (Huang and Rust, 2020; Lee and Sathikh, 2013). Drawing on Pradeep et al. (2019), we classify the following H2MP sub-types:

First, robotic process automation-based platforms computerize existing labor-intensive processes. They operate through rule-based automation, where linear algorithms are used to answer basic queries through sensor-based signals (Hollebeek et al., 2020c). For example, when using call center menus or television remote controls, consumers signal their desired activity (e.g. call center: by pressing "1" to obtain their account details, "2" to change their address, etc.), which in turn activate particular predetermined, automated responses. Robotic process automation thus reflects a low level of artificial intelligence that responds to the user's data request, without learning or adapting its actions in the process (Huang and Rust, 2018; Pradeep et al. 2019).

Second, machine/deep learning-based platforms function relatively autonomously and auto-adjust their actions to either meet or pre-empt user needs, without necessitating human intervention or support (Mende et al., 2019). These platforms' underlying machine/deep learning algorithms help them make increasingly accurate predictions of user needs or behaviors (Marr, 2018; Chen and Lin, 2014), improving their performance over time. To raise their predictive accuracy, H2MPs rely on large volumes of training data, revealing big data's crucial role (Hollebeek et al., 2020c; Arthur, 2013). Examples of these platforms include predictive SMS/email, service robots (e.g. robotic waiters/hotel receptionists), chatbots, social robots (e.g. Pepper used to meet-and-greet clients), medical robots, intelligent personal assistants (e.g. Watson), autonomous or self-driving cars, and Internet-of-Things-based devices (e.g. smart home appliances; Kumar et al., 2016; Chérif and Lemoine, 2018; Wirtz et al., 2018; Ng and Wakenshaw, 2017; Goudey and Bonnin, 2016; Leicht et al., 2018).

Our digital platform types can operate independently, but they may also be connected to one another. For example, a social media page might record a consumer's click-stream data, which it then transmits to an H2MP-based machine learning algorithm to identify those products the user is deemed to be interested in based on his/her search history (Chen and Lien, 2014). In these cases, characteristics of each deployed digital platform need to be considered. However, while the machine-to-machine interactions inherent in integrated forms of our digital platform types offer important back-office processes (Schweitzer et al., 2019; Chen et al., 2012), we exclude these from our digital platform typology because they are invisible to users. For example, though artificially intelligent applications may drive particular (e.g. advertising) content displayed in social gaming, the game remains the consumer's primary interactive platform. As such, machine-to-machine 
interactions operating in the background fall outside of our typology's ambit. Moreover, machineto-machine interactions depart from CDCV's scope, which involves the consumer's active "doing" (McColl-Kennedy et al., 2012), as discussed. Next, we develop a social presence theory-informed framework of CDCV.

\section{Social presence theory-informed conceptual framework and propositions of CDCV}

Social presence theory examines the ability of communication platforms to transmit social cues and generate user-perceived platform intimacy and immediacy, which differ across platforms (Short et al., 1976; Gooch and Watts, 2015). Consequently, different digital platforms differentially affect user-perceived value (Song et al., 2008). For example, while email typically reveals lower intimacy and immediacy levels, these tend to be higher for video-calling platforms that transmit more extensive social cues (e.g. Zoom), thus enhancing their value-creating capacity (Nakanishi et al., 2011). However, though prior researchers have explored platform intimacy and/or immediacy's effect on user-perceived value (e.g. Song and Hollenbeck, 2015), their respective effects on interactive CDCV remain tenuous, as therefore explored in this paper. Specifically, we expect higher levels of perceived digital platform intimacy and immediacy to favorably impact CDCV. While intimacy and immediacy tend to be optimized in face-to-face interactions, we focus on their manifestation through digital platforms (Osei-Frimpong and McLean, 2018; Van Doorn et al., 2017) and their respective impact on CDCV.

As noted, social presence theory proposes that perceived platform intimacy and immediacy drive users' platform evaluations (Short et al., 1976; Lombard and Ditton, 1997; Tu, 2000). First, intimacy reflects a digital platform's user-perceived ability to spark warmth, closeness, or belonging to one's interaction partner (Baek et al., 2018; Van Doorn et al., 2017). Intimacy is commonly believed to be a function of interaction partners' physical distance, conversation topics, and non-verbal communication (Argyle and Dean, 1968; Tu, 2000). Of these, non-verbal communication or the extent to which a platform affords the use of non-spoken elements in exchange (e.g. eye contact, smiling, body language; Birdwhistell, 1970), is directly affected by the deployed digital platform (e.g. greater non-verbal communication through video-conferencing-vs. SMS platforms). However, despite their differences, most digital platforms, at a minimum, permit the use of paralanguage. Paralanguage refers to "written manifestations of nonverbal... (e.g. tactile, visual, tone) elements that supplement or replace written language and that can be expressed through words, symbols, images, punctuation, demarcations, or any combination of these" (Luangrath et al., 2017, p. 98), including emoji (Hill, 2016). Generally, the greater the range of non-verbal cues used on or through a digital platform, the higher its perceived intimacy (Hopkins, 2020). 
Second, immediacy is a digital platform's user-perceived capacity to give urgency or importance to an exchange (e.g. by recipients promptly viewing and responding to a message; Wiener and Mehrabian, 1968), which also differs across platforms. For example, instant-messaging tends to receive a faster reply than web-based enquiry forms. Typically, prompter responses foster rising platform immediacy (Gunawardena and Zittle, 1997). While immediacy comprises two main elements, including (a) the platform's capacity to fashion a timely response, and (b) the recipient's decision regarding when to respond, we highlight immediacy's former, digital platform-based aspect. Here, a necessary condition for high immediacy is elevated user-perceived platform efficiency, or its reliability in transmitting a message or content to its recipient(s) (Short et al., 1976; Smedlund et al., 2015). We introduce our social presence theory-informed framework, which explores digital platform intimacy's and immediacy's effect on CDCV below (see Fig. 1).

\section{Insert Fig. 1 about here}

We posit that the deployed digital platform affects the association of social presence theory's intimacy/immediacy and CDCV, as shown in Fig. 1. Below, we develop a set of Propositions that detail the framework's associations for our suggested digital platforms. First, social presence theory's intimacy reflects a platform's user-perceived capacity to foster closeness to one's interaction partner (Short et al., 1976), as discussed. In addition, H2HPs act as the gobetween in connecting users, revealing their chiefly relational or communicational role. However, H2MPs primarily assist users to more efficiently or effectively execute particular tasks (e.g. smart home appliances), exposing their more utilitarian nature (Voss et al., 2003). We therefore infer that present-day H2HPs are likely to generate higher user-perceived intimacy than H2MPs. Still, as machine/deep learning-based H2MPs continue to develop, we anticipate them to possess an increasingly relational capacity over time (e.g. virtual personal assistants forming bonds with their users; Van Doorn et al., 2017). We thus posit (also see Fig. 1):

P1a: Contemporary H2HPs (vs. H2MPs) typically generate higher user-perceived intimacy, yielding the former's greater contribution to $C D C V$ in this regard. However, as machine/deep learning-based H2MPs develop to fulfil an increasingly relational role, their capacity to foster user-perceived intimacy will rise over time.

We next compare our H2MP sub-categories of robotic process automation- and machine/deep learning-based platforms. While the latter are able to 'learn' by adjusting or finetuning their actions to offer increasingly user-preferred suggestions or solutions, the former merely respond to users' sensor-based signals, without evolving or learning (Pradeep et al., 2019; Huang and Rust, 2018). We therefore expect machine/deep learning-based platforms to get closer to the 
consumer, thus developing more bonded relationships (vs. robotic process automation-based platforms). We stipulate (also see Fig. 1):

P1b: Machine/deep learning (vs. robotic process automation)-based H2MPs typically generate higher user-perceived intimacy, yielding the former's greater contribution to $C D C V$ in this regard.

Second, social presence theory's immediacy denotes a digital platform's perceived ability to give urgency to an exchange (Short et al., 1976), which we also expect to differ across platforms. For example, H2HPs deliver messages or content to platform users and allow them to interact (Hollebeek et al., 2014). As recipients may view or respond to messages at their discretion, interactions can feature a response delay (Wu et al., 2014). Consumers may also overlook messages or content posted on these platforms, yielding their potential tardy or non-response and incurring low immediacy (e.g. in online communities). However, as H2MPs are users' interaction partner (Mende et al., 2019), they typically offer a prompter response than H2HPs, given their real-time presence in interactions. We postulate (also see Fig. 1):

P2a: H2MPs (vs. H2HPs) typically generate higher perceived platform immediacy, yielding the former's elevated contribution to CDCV in this regard.

We next compare the immediacy of our H2MP sub-categories. First, robotic process automation-based platforms mechanize existing labor-intensive, mundane processes (Pradeep et al., 2019), as outlined. These platforms' high immediacy tends to be coupled with a high accuracy level of their response to user prompts in executing particular tasks (Willcocks et al., 2015). Consequently, these platforms' consistent, timely user response can facilitate their stable contribution to $\mathrm{CDCV}$, when users continue to steadily value their platform interactions over time. However, these platforms' high immediacy may also see a dwindling contribution to CDCV, as consumers grow increasingly accustomed to using the platform's functionality, lowering their evaluations thereof over time (Heitz et al., 2019; Hollebeek et al., 2020c). By contrast, machine/deep learning-based platforms' high immediacy is subject to low initial, but gradually improving accuracy over time (Pradeep et al., 2019), yielding an increasingly positive contribution to CDCV. We formulate (also see Fig. 1):

P2b: Robotic process automation-based platforms' high immediacy typically makes a stable or declining contribution to CDCV. However, machine/deep learning-based platforms' high immediacy is likely to make a growing contribution to CDCV over repeated interactions.

\section{Discussion and implications}

We next discuss important implications that arise from our analyses, followed by an overview of limitations of this research, from which we develop avenues for further investigation. 


\section{Theoretical implications}

We first offer generic observations about the current state of cocreated value research and its general repercussions for the field, followed by a discussion of specific implications that arise from our framework and Propositions of CDCV.

Generic theoretical implications. We offer the following reflections on the present state of cocreated value research. First, disparities of insight regarding cocreated value's conceptualization and the increasing range of cocreated value-related concepts require scholarly attention. For example, researchers are exploring concepts including cocreated value, cocreated brands, cocreated brand equity, cocreated experience, cocreated knowledge, cocreated social responsibility, cocreated service recovery, cocreated health awareness, and so on (Gyrd-Jones and Kornum, 2013; Kull and Heath, 2016; Helm and Jones, 2010; Mahr et al., 2014; Mossberg et al., 2014; Dong et al., 2008). However, the deployment of these differing concepts - often, to denote highly similar ideas - runs the risk of developing fragmented, myopic insight (Ranjan and Read, 2016; Hollebeek et al., 2019). What is therefore needed is rigorous, cocreated value-consolidating research that takes stock and identifies the concept's generalizable hallmarks.

Second and relatedly, understanding of cocreated value's nomological network is becoming increasingly blurred. Authors using differing theoretical lenses to explore cocreated value, including S-D logic (Vargo and Lusch, 2010), social exchange theory (Grace and Iacono, 2015), or motivation theory (Chou and Chen, 2018), typically propose unique sets of antecedents and consequences. What is therefore needed is further research that unifies cocreated value-based acumen across theoretical perspectives (e.g. by integrating CDCV drivers/outcomes rooted in different perspectives in unifying frameworks; Saha et al., 2020).

Third, we developed a social presence theory-informed framework and an associated set of Propositions of CDCV, which highlight digital platform-perceived intimacy's and immediacy's conducive effect on CDCV. That is, we expect those digital platforms that optimize user-perceived intimacy and immediacy to foremostly boost CDCV. However, future empirical research is required to test and validate our purely conceptual findings. Below, we detail specific implications from our framework and Propositions of CDCV.

Implications arising from our framework and propositions of CDCV. Our framework and Propositions advance insight into CDCV from a social presence theory perspective, which remains nebulous to-date (Huber et al., 2017; Kristensson et al., 2008; Song et al., 2008). Below, we detail major implications that emerge from our findings, as structured by our Propositions (please also refer the specific research questions listed in Table 1). 


\section{Insert Table 1 about here}

First, P1a reads "Contemporary H2HPs (vs. H2MPs) typically generate higher userperceived intimacy, yielding the former's greater contribution to CDCV in this regard. However, as machineldeep learning-based H2MPs develop to fulfil an increasingly relational role, their capacity to foster user-perceived intimacy will rise over time." In social presence theory, a platform's ability to yield user-perceived intimacy is key (Short et al., 1976; Osei-Frimpong and McLean, 2018). While we anticipate contemporary H2HPs' (vs. H2MPs') greater ability to generate consumer-perceived intimacy and CDCV, as outlined, ongoing artificial intelligence developments and growing consumer acceptance of these solutions will taper the gap over time. Going forward, it is therefore of interest to explore best H2MP design practices (e.g. in what ways should these platforms approximate (vs. differ from) human behavior in exchange?; Kim et al., 2019).

Comparing our H2MP sub-categories, P1b states: "Machine/deep learning (vs. robotic process automation)-based H2MPs typically generate higher user-perceived intimacy, yielding the former's greater contribution to CDCV in this regard." Robotic process automation-based platforms are primarily used to computerize laborious tasks (Pradeep et al., 2019). Owing to their utilitarian focus, these platforms' capacity to yield user-perceived intimacy, and thus CDCV, is limited. However, equipped with the ability to interpret consumers' (non-)verbal cues and predict user needs, machine/deep learning-based platforms propose solutions that are deemed desirable to users (Huang and Rust, 2020), thus fostering a level of intimacy (e.g. through personalized offers). However, a better understanding is required regarding these platforms' respective capacity to generate user-perceived intimacy/immediacy and CDCV. For example, how should machine/deep learning algorithms be programmed to lift platform intimacy?

P2a posits: "H2MPs (vs. H2HPs) typically generate higher perceived platform immediacy, yielding the former's elevated contribution to CDCV in this regard." As H2HPs connect human actors, their response to the sender might be delayed, though H2MPs tend to offer more immediate user feedback (Pradeep et al., 2019). We therefore expect H2MPs (vs. H2HPs) to make a greater contribution to $\mathrm{CDCV}$. However, these assertions require future empirical testing and validation. For example, how do H2HP interactions that feature an immediate response stack up against H2MP interactions in terms of their respective CDCV? What is the relative importance of a digital platform's immediacy vis-à-vis its capacity to generate user-perceived intimacy, or (how) may these factors interact to drive CDCV? 
P2b states: “Robotic process automation-based platforms' high immediacy typically makes a stable or declining contribution to CDCV. However, machine/deep learning-based platforms' high immediacy is likely to make a growing contribution to CDCV over repeated interactions." As discussed, robotic process automation-based platforms mechanize relatively straightforward tasks. By contrast, machine/deep learning-based platforms can be used to predict or anticipate consumer needs (Huang and Rust, 2018). Therefore, as consumers get used to interacting with robotic process automation-based platforms, CDCV tends to either remain stable or dwindle over time, as outlined. However, as machine/deep learning-based platforms' predictive accuracy improves over repeated interactions (Mende et al., 2019), we expect these platforms to make a rising contribution to CDCV. However, questions that remain include: What machine/deep learning features are particularly conducive in boosting CDCV? Which tactics can robotic process automation-based platforms deploy to halt or decelerate CDCV's demise? We next apply our Propositions to marketing practice to illustrate their practical applicability.

\section{Practical implications}

In addition to its theoretical implications, this research also generates noteworthy implications for digital platform design and implementation, as discussed below. First, P1a reads “Contemporary H2HPs (vs. H2MPs) typically generate higher user-perceived intimacy, yielding the former's greater contribution to CDCV in this regard. However, as machine/deep learningbased H2MPs develop to fulfil an increasingly relational role, their capacity to foster userperceived intimacy will rise over time." Managers need to understand the extent to and occasions on which consumers wish to form close bonds with their interaction partner (Gummesson, 2011). In these cases, we recommend primarily adopting H2HPs to optimize CDCV, given these platforms' core user-connecting, relational role. However, contexts requiring more distant interactions are better served by less intimate H2MPs (e.g. robotic process automation-based platforms). However, as P1a states, we anticipate H2HPs' relative relational advantage (vs. H2MPs) to diminish as machine/deep learning-based H2MPs' relational capacity continues to expand over time (Pradeep et al., 2019), lifting their capacity to foster close user bonds.

Second, P1b posits: "Machine/deep learning (vs. robotic process automation)-based H2MPs typically generate higher user-perceived intimacy, yielding the former's greater contribution to CDCV in this regard." While robotic process automation-based platforms computerize routine tasks, they do not evolve or adjust their actions based on user feedback, as discussed. However, given their capacity to learn, machine/deep learning-based platforms autonomously regulate their behavior for enhanced user outcomes (Huang and Rust, 2020). To optimize CDCV, we thus recommend the latter (vs. former) platforms, particularly because robotic 
process automation-based platforms' CDCV-generating capacity can also decline over time (see $\mathrm{P} 2 \mathrm{~b}$ ). As stated, these platforms can also be deployed together (e.g. using robotic process automation-based platforms to facilitate low-level tasks, which activate relevant artificially intelligent applications; Pradeep et al., 2019).

Third, P2a proposes: "H2MPs (vs. H2HPs) typically generate higher perceived platform immediacy, yielding the former's elevated contribution to CDCV in this regard." H2HPs can incur a delayed response, as users may access and respond to messages or content in their own time, as discussed. However, for H2MPs, the platform's response immediacy - coupled with its accuracy is decisive in user evaluations. Therefore, in contexts demanding high urgency, highly immediate platforms that offer instant feedback (e.g. live chat) should be used (Lv et al., 2018). However, less time-sensitive occasions (e.g. peer review processes) can see the adoption of less immediate platforms (e.g. email), which may incur lower cost (Rice, 1993).

Finally, P2b states: "Robotic process automation-based platforms' high immediacy typically makes a stable or declining contribution to CDCV. However, machineldeep learningbased platforms' high immediacy is likely to make a growing contribution to CDCV over repeated interactions." Stable user evaluations of robotic process automation-based platforms will tend to make a relatively low contribution to $\mathrm{CDCV}$, owing to the mundane nature of their tasks (Hollebeek et al., 2020c). However, consumer assessments of these platforms may also decline (e.g. as they become habituated to using these platforms; Heitz et al., 2019). By contrast, through their capacity to learn, machine/deep learning-based platforms tend to make a growing contribution to CDCV, as outlined. Yet, as a caveat, the garbage in, garbage out (GIGO) principle applies to these latter platforms (Weyerer and Langer, 2019). That is, the use of low-quality training data yields these platforms' deteriorating (vs. improving) performance, thereby either lowering CDCV or turning it into codestroyed value. Consequently, we recommend using H2MPs (vs. H2HPs) to optimize platform immediacy, provided their solutions feature high response accuracy. To secure their high (and rising) accuracy, these platforms require large volumes of high-quality training data on an ongoing basis (Pradeep et al., 2019).

\section{Limitations and further research}

This research has several limitations that offer opportunities for further study. First, the framework's conceptual nature necessitates its future empirical testing and validation (Yadav, 2010). In this vein, it is of interest to better understand the relative contribution of our identified social presence theory-informed antecedents to CDCV. For example, if a digital platform's perceived intimacy is identified as paramount CDCV driver, then its development (vs. that of 
immediacy) should be prioritized. In addition, how can consumer-perceived digital platform intimacy and immediacy be nurtured to raise CDCV? Which consequences may CDCV generate? Moreover, though we address consumer-perceived CDCV, future studies could adopt a two-sided (e.g. consumer/firm) or broader-actor perspective of digital cocreated value (Lenka et al., 2016; Alexander et al., 2018), including by quantifying multiple actors' likely asymmetric value that arises from digital interactions (Edvardsson et al., 2011; Clark et al., 2020).

Second and relatedly, our digital platform typology requires empirical validation. For example, future experiments may manipulate key H2HP/H2MP tenets to derive further insight (e.g. extensive vs. limited relational/functional attributes; Fisher, 1971). Given their novelty and rapid advancement, H2MPs in particular warrant further research (Mende et al., 2019). For example, we expect to see the increasing integration of utilitarian and more social (e.g. companionship) functionality in future H2MPs, as discussed. We thus anticipate these platforms' growing relational capacity, leading consumers to develop a rising attachment to these platforms, particularly in some cultures (Kitano, 2006; Hollebeek, 2018), which merits further study. Consequently, progressively relational H2MPs are best viewed on a functional-to-relational continuum. Despite these developments, we expect our digital platform typology to hold, as H2MPs - while fulfilling a potential relational role - are not designed to enable human-to-human interactions, like H2HPs (Marin et al., 2009). Given humans' innate belonging need (Maslow, 1954), we expect an ongoing desire for H2HP-based interactions, though their nature may change over time. Sample issues for investigation include: Which digital platforms are most conducive to optimizing CDCV, whilst minimizing digital codestroyed value? How will H2MPs' increasingly relational functionality affect CDCV?

Third, it is of interest to explore the theoretical associations proposed in Fig. 1 for consumers using multiple digital platforms (Uhrich, 2014). For example, which platforms do consumers typically use together, how do users perceive different platforms' intimacy and immediacy across customer segments, and how does consumers' integrative platform use affect CDCV? Consequently, to what extent should H2HPs and H2MPs be jointly designed to optimize CDCV for multi-platform users (Tixier et al., 2010; Belboula et al., 2018)? How can H2HP/H2MP design stimulate negative-to-positive CDCV valence shifts, while minimizing reverse swings (Bowden et al., 2017)?

Fourth, we encourage further research that investigates CDCV within broader, alternate, or unifying nomological networks, which may be compared to our social presence theory-informed analyses (Short et al., 1976; Osei-Frimpong and McLean, 2018). Thus, though social presence 
theory offers an appropriate lens for exploring CDCV across (digital) platforms, alternatives exist (e.g. social exchange- or motivation theory), as discussed. These future findings could be contrasted to or integrated with ours (e.g. to complement or refine our insight). 
Fig. 1: Conceptual framework

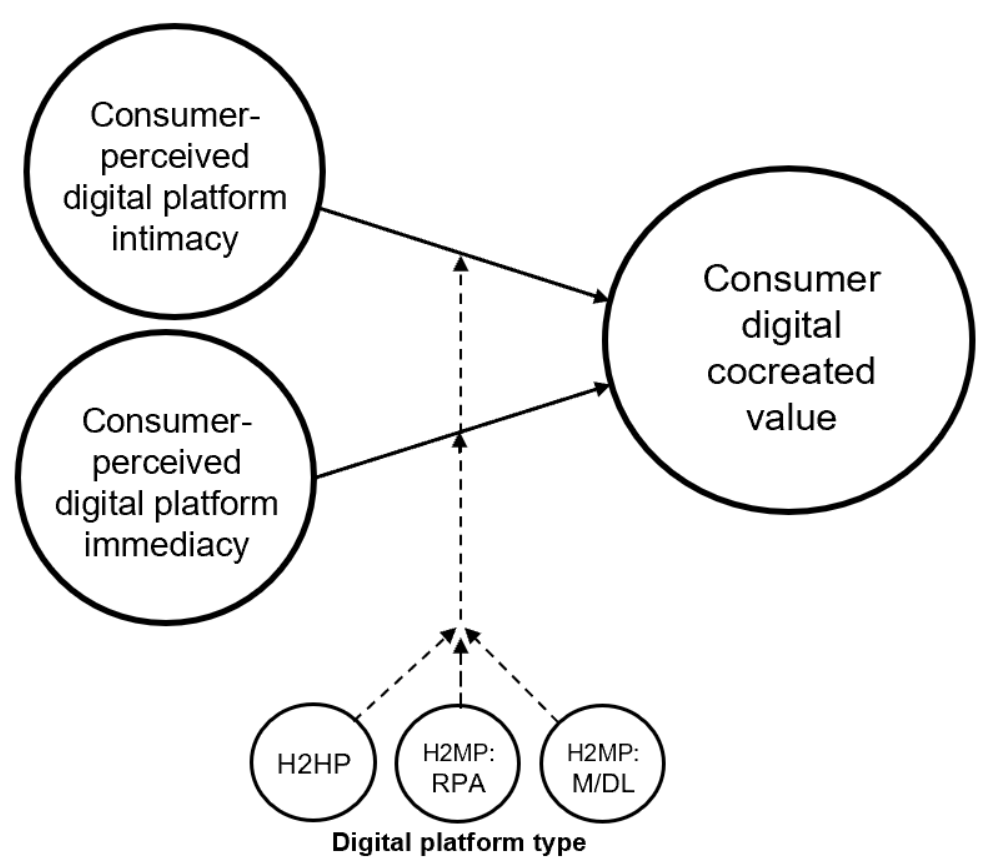

Notes - H2HP: Human-to-human platform; H2MP: Human-to-machine platform; RPA: Robotic process automation-based platform; M/DL: Machine/deep learning-based platform. 


\section{Table 1: Sample Research Questions}

\section{Proposition}

P1a: Contemporary H2HPs (vs. H2MPs) typically generate higher user-perceived intimacy, yielding the former's greater contribution to CDCV in this regard. However, as machine/deep learning-based H2MPs fulfil an increasingly relational role, thei capacity to foster user-perceived intimacy will rise over time.

P1b: Machine/deep learning (vs. robotic process automation)based H2MPs typically generate higher user-perceived intimacy, yielding the former's greater contribution to $\mathrm{CDCV}$ in this regard.

P2a: H2MPs (vs. H2HPs) typically generate higher perceived platform immediacy, yielding the former's elevated contribution to $\mathrm{CDCV}$ in this regard.

P2b: Robotic process automation-based platforms' high immediacy typically makes a stable or declining contribution to CDCV. However, machine/deep learning-based platforms' high immediacy is likely to make a growing contribution to $\mathrm{CDCV}$ over repeated interactions.

\section{Sample Research Questions}

What is digital platform intimacy's effect on CDCV for particular H2HPs and H2MPs (Osei-Frimpong \& McLean, 2018)? How does a digital platform's perceived intimacy affect the value cocreated (or codestroyed) with firms vs. fellow consumers?

What is the relative contribution of a platform's intimacy to CDCV (e.g. explored by conducting conjoint experiments)? Do intimacy and immediacy interact to affect CDCV in particular digital contexts (Hair et al., 2018)?

How does consumers' multiple digital platform use affect each platform's individual/joint effect on CDC What is the best composition of digital platforms to optimize consumer-perceived platform intimacy?

How do specific (e.g. relational/functional) H2HP/H2MP attributes affect CDCV?

What is the effect of a digital platform's perceived immediacy on CDCV across platform types (Li et al., 2018)?

How does an H2MP's (vs. H2HP's) perceived immediacy influence the value cocreated/codestroyed with firms vs. consumers?

o Which are the chief H2HP/H2MP attributes that contribute to platform immediacy, and how do these affect CDCV? How will H2MPs' growing relational role progressively complement or compete with H2HPs?

\section{respectively (Smith, 2013)?}

If consumers use multiple digital platforms, (how) does this affect each platform's respective contribution to CDCV?

How can H2HPs' declining contribution to CDCV be minimized or reversed (Hollebeek et al., 2020b)? 


\section{References}

Akaka, M., Vargo, S., and Lusch, R. (2012), An exploration of networks in value co-creation: A service-ecosystems view, Review of Marketing Research, 9: 13-50.

Alexander, M., Jaakkola, E., and Hollebeek, L. (2018), Zooming out: Actor engagement beyond the dyadic, Journal of Service Management, 29(3): 333-351.

Algharabat, R. (2018), The role of telepresence and user engagement in cocreation value and purchase intention: Online retail context, Journal of Internet Commerce, 17(1): 1-25.

Alves, H., Fernandes, C., and Raposo, M. (2016), Value co-creation: Concept and contexts of application and study, Journal of Business Research, 69(5): 1626-1633.

Anderson, J. (1995), Relationships in business markets: Exchange episodes, value creation, and their empirical assessment. Journal of the Academy of Marketing Science, 23(4): 346-350.

Argyle, M., Lalljee, M., and Cook, M. (1968), The effects of visibility on interaction in the dyad, Human Relations, 21: 3-17.

Arthur, L. (2013), Big Data Marketing, Wiley.

Baek, E., Choo, H., and Lee, S. (2018), Using warmth as the visual design of a store: Intimacy, relational needs, and approach intentions, Journal of Business Research, 88: 91-101.

Bailey, D., Pitelis, C., and Tomlinson, P. (2018), A place-based developmental regional industrial strategy for sustainable capture of co-created value. Cambridge Journal of Economics, 42(6): 1521-1522.

Balaji, M. and Roy, S. (2017), Value co-creation with Internet of Things technology in the retail industry, Journal of Marketing Management, 33(1-2): 7-31.

Banker, R., Mitra, S., and Sambamurthy, V. (2011), The effects of digital trading platforms on commodity prices in agricultural supply chains, MIS Quarterly, 35(3): 599-611.

Belboula, I., Ackermann, C., and Mathieu, J. (2018), Product design and hierarchized persuasion process: An application to three household electrical products, Recherche et Applications en Marketing, 33(4): 2-23.

Bernal-Merino, M. (2016), Glocalization and co-creation: Trends in international game production. In: Esser, A., Smith, I., and Bernal-Merino, M. (Eds.), Media Across Borders, Routledge.

Bèzes, C. (2019), What kind of in-store smart retailing for an omnichannel real-life experience? Recherche et Applications en Marketing, 34(1): 91-112.

Birdwhistell, R. (1970), Kinesics and Context, Philadelphia: University of Philadelphia Press.

Black, H. and Gallan, S. (2015), Transformative service networks: Cocreated value as well-being, Service Industries Journal, 35(15-16): 826-845.

Bolton, R. and Saxena-Iyer, S. (2009), Interactive services: A framework, synthesis and research directions," Journal of Interactive Marketing, 23(1): 91-104.

Bowden, J., Conduit, J., Luoma-Aho, V., Hollebeek, L., and Solem, B. (2017), Engagement valence duality and spillover effects in online brand communities. Journal of Service Theory and Practice, 27(4): 877-897.

Breidbach, C., Brodie, R., and Hollebeek, L. (2014), Beyond virtuality: From engagement platforms to engagement ecosystems, Managing Service Quality, 24(6): 592-611.

Breidbach, C. and Maglio, P. (2016), Technology-enabled value co-creation: An empirical analysis of actors, resources, and practices, Industrial Marketing Management, 56: 73-85.

Brodie, R., Ilic, A., Juric, B. and Hollebeek, L. (2013), Consumer engagement in a virtual brand community: An exploratory analysis, Journal of Business Research, 66(1): 105-114.

Brodie, R., Jaakkkola, E., Fehrer, J., Hollebeek, L., and Conduit, J. (2016), From customer to actor engagement: Exploring a broadened domain. EMAC, Oslo.

Brzozowski, M., Hogg, T., and Szabo, G. (2008), Friends and foes: Ideological social networking, SIGCHI Conference on Human Factors in Computing Systems, 817-820.

Buonincontri, P., Morvillo, A., Okumus, F. and Van Niekerk, M. (2017), Managing the experience co-creation process in tourism destinations: Empirical findings from Naples, Tourism Management, 62(Oct): 264-277.

Busser, J. and Shulga, L. (2018), Co-created value: Multidimensional scale and nomological network, Tourism Management, 65(Apr): 69-86.

Cabiddu, F., Lui, T., and Piccoli, G. (2013), Managing value co-creation in the tourism industry, Annals of Tourism Research, 42(Jul): 86-107.

Caic, M., Odekerken-Schröder, G., and Mahr, D. (2018), Service robots: Value co-creation and co-destruction in elderly care networks, Journal of Service Management, 29(2): 178-205.

Chandler, J. and Vargo, S. (2011), Contextualization and value-in-context: How context frames exchange, Marketing Theory, 11(1): 35-49.

Chen, K. and Lien, S. (2014), Machine-to-machine communications: Technologies and challenges, Ad Hoc Networks, 18(Jul): 3-23.

Chen, M., Wan, J., and Li, F. (2012), Machine-to-machine communication: Architectures, standards, and applications, KSII Transactions on Internet and Information Systems, 6(2): 480-497. 
Chen, T., Drennan, J., Andrews, L., and Hollebeek, L. (2018), User experience sharing: Understanding customer initiation of value co-creation in online communities, European Journal of Marketing, 52(5/6): 1154-1184.

Chen, X. and Lin, X. (2014), Big data deep learning: Challenges and perspectives, IEEE Xplore. Accessed: https://ieeexplore.ieee.org/abstract/document/6817512.

Chérif, E. and Lemoine, J-F. (2018), Anthropomorphic virtual assistants and the reactions of internet users: An experiment on the assistant's voice, Recherche et Applications en Marketing, 34(1): 28-47.

Chou, S. and Chen, Y. (2018), The impact of money and task complexity on consumer co-creation intention, Marketing Review, 15(1): 67-100.

Chumpitaz Cáceres, R., and Paparoidamis, N. (2007), Service quality, relationship satisfaction, trust, commitment and business-to-business loyalty, European Journal of Marketing, 41(7/8): 836-867.

Clark, M., Lages, R., and Hollebeek, L. (2020), Friend or foe? Customer engagement's value-based effects on fellow customers and the firm, Journal of Business Research, In press, DOI: https://doi.org/10.1016/j.jbusres.2020.03.011.

Cova, B., Dalli, D., and Zwick, D. (2011), Critical perspectives on consumers' role as producers: Broadening the debate on value co-creation in marketing processes, Marketing Theory, 11(3): 231-241.

Cova, B. and Salle, R. (2008), Marketing solutions in accordance with the S-D logic: Co-creating value with customer network actors, Industrial Marketing Management, 37(3): 270-277.

Dahl, A., Milne, G., and Peltier, J. (2019), Digital health information seeking in an omni-channel environment: A shared decision-making and service-dominant logic perspective, Journal of Business Research, In press, DOI: https://doi.org/10.1016/j.jbusres.2019.02.025.

Dampérat, M., Jeannot, F., Jongmans, E., and Jolibert, A. (2019), Modeling a cocreative process: The contributions of design and management, Recherche et Applications en Marketing, 34(3): 111-137.

Daunt, K. and Harris, L. (2017), Customer showrooming: Value co-destruction, Journal of Retailing and Consumer Services, 38(Sep): 166-176.

Delpechitre, D., Beeler-Connelly, L., and Chaker, N. (2018), Customer value co-creation behavior: A dyadic exploration of the influence of salesperson emotional intelligence on customer participation and citizenship behavior, Journal of Business Research, 92(Nov): 9-24.

Dong, B., Evans, K., and Zou, S. (2008), The effects of customer participation in co-created service recovery, Journal of the Academy of Marketing Science, 36(1): 123-137.

Dong, B. and Sivakumar, K. (2017), Customer participation in services: Domain, scope, and boundaries, Journal of the Academy of Marketing Science, 45(6): 944-965.

Drucker, P. (2011), Technology, Management, and Society, Harvard Business Review Press.

Echeverri, P. and Skålén, P. (2011), Co-creation and co-destruction: A practice-theory based study of interactive value formation, Marketing Theory, 11(3): 351-373.

Edvardsson, B., Tronvol, B., and Gruber, T. (2011), Expanding understanding of service exchange and value co-creation: A social construction approach, Journal of the Academy of Marketing Science, 39(2): 327-339.

Fisher, R. (1971), The Design of Experiments, MacMillan.

Fournier, A. (2019). My Starbucks idea: An open innovation case study. March 20. Accessed (Jun 7, 2020) at: https://www.braineet.com/blog/my-starbucks-idea-case-study/.

Füller, J. (2010), Refining virtual co-creation from a consumer perspective, California Management Review, 52(2): 98.

Gebauer, J., Füller, J., and Pezzei, R. (2013), The dark and the bright side of co-creation: Triggers of member behavior in online innovation communities, Journal of Business Research, 66(9): 1516-1527.

Go Jefferies, J., Bishop, S., and Hibbert, S. (2019), Service innovation through resource integration: An empirical examination of co-created value using telehealth services, Public Policy and Administration, DOI: https://doi.org/10.1177/0952076718822715.

Gooch, D. and Watts, L. (2015), The impact of social presence on feelings of closeness in personal relationships, Interacting with Computers, 27(6): 661-674.

Goudey, A. and Bonnin, G. (2016), Must smart objects look human? Study of the impact of anthropomorphism on the acceptance of companion robots, Recherche et Applications en Marketing, 31(2): 2-20.

Grace, D. and Iacono, J. (2015), Value creation: An internal customer's perspective, Journal of Services Marketing, 29(6/7): 560-570.

Granovetter, M. (1983), The strength of weak ties: A network theory revisited, Sociological Theory, 1: 201-233.

Grissemann, U. and Stokburger-Sauer, N. (2012), Customer co-creation of travel services: The role of company support and customer satisfaction with the co-creation performance, Tourism Management, 33(6): 1483-1492.

Grönroos, C. and Voima, P. (2013), Critical service logic: Making sense of value creation and co-creation, Journal of the Academy of Marketing Science, 41(2): 133-150.

Gummesson, E. (2011), Total Relationship Marketing, BH Publishing.

Gummesson, E. and Mele, C. (2010), Marketing as value co-creation through network interaction and resource integration, Journal of Business Market Management, 4(4): 181-198. 
Gunawardena, C. and Zittle, F. (1997), Social presence as a predictor of satisfaction within a computer-mediated conferencing environment, American Journal of Distance Education, 11(3): 8-26.

Gyrd-Jones, R. and Kornum, N. (2013), Managing the co-created brand: Value and cultural complementarity in online and offline multi-stakeholder ecosystems, Journal of Business Research, 66(9): 1484-1493.

Hair, J., Black, W., Babin, B., and Anderson, R. (2018), Multivariate Data Analysis, Pearson.

Hambrick, D. (1984), Taxonomic approaches to studying strategy: Some conceptual and methodological issues, Journal of Management, 10(1): 27-41.

He, W. and Yan, G. (2015), Mining blogs and forums to understand the use of social media in customer co-creation, Computer Journal, 58(9): 1909-1920.

Heidenreich, S., Wittowski, K., Handrich, M., and Falk, T. (2014), The dark side of customer co-creation: Exploring the consequences of failed co-created services, Journal of the Academy of Marketing Science, 43(3): 279-296.

Heitz, C., Blume, M., Scherrer, C., Stöckle, R. and Bachmann, T. (2019), Designing value co-creation for a free-floating e-bike sharing system, INFORMS-CSS 2019: Smart Service Systems, Operations Management, and Analytics: 113-125.

Helm, C. and Jones, R. (2010), Extending the value chain - A conceptual framework for managing the governance of cocreated brand equity, Journal of Brand Management, 17(8): 579-589.

Hill, J. (2016), The impact of emojis and emoticons on online consumer reviews, perceived company response quality, brand relationship, and purchase intent, Accessed (Jun 7, 2020) at: https://scholarcommons.usf.edu/etd/6513/.

Hollebeek, L. (2019), Developing business customer engagement through social media engagement-platforms: An integrative S-D logic/RBV-informed model, Industrial Marketing Management, 81(Aug): 89-98.

Hollebeek, L., Clark, M., Andreassen, T., Sigurdsson, V., and Smith, D. (2020a), Virtual reality through the customer journey, Journal of Retailing \& Consumer Services, In press, DOI: https://doi.org/10.1016/j.jretconser.2020.102056.

Hollebeek, L., Clark, M., Hammedi, W., and Arvola, R. (2020b). Cocreated brand value: Framework and propositions, Working paper.

Hollebeek, L., Sprott, D., and Brady, M. (2020c), Rise of the machines? Customer engagement in automated service interactions, Working Paper.

Hollebeek, L., Srivastava, R., and Chen, T. (2019), S-D logic-informed customer engagement: Integrative framework, revised fundamental propositions, and application to CRM, Journal of the Academy of Marketing Science, 47(1): $161-185$.

Hopkins, J. (2020), The concept of affordances in digital media, Handbuch Soziale Praktiken und Digitale Alltagswelten, 47-54.

Huang, M.H. and Rust, R. (2018), Artificial intelligence in service, Journal of Service Research, 21(2): 155-172.

Huang, M.H. and Rust, R. (2020), Engaged to a robot? The role of AI in service, Journal of Service Research, In press, DOI: https://doi.org/10.1177/1094670520902266.

Huber, T., Kude, T. and Dibbern, J. (2017). Governance practices in platform ecosystems: Navigating tensions between cocreated value and governance costs. Information Systems Research, 28(3): 451.

Hult, G.T., Mena, J., Ferrell, O.C., and Ferrell, L. (2011), Stakeholder marketing: A definition and conceptual framework, AMS Review, 1(1): 44-65.

Humphreys, A. and Grayson, K. (2008), The intersecting roles of consumer and producer: A critical perspective on coproduction, co-creation and presumption, Sociology Compass, 2(3): 963-980.

Kannan, P. and Li, H. (2017), Digital marketing: A framework, review and research agenda, International Journal of Research in Marketing, 34: 22-45.

Keeling, D., De Ruyter, K., Mousavi, S., and Laing, A. (2019), Technology push without a patient pull: Examining digital unengagement (DU) with online health services, European Journal of Marketing, 53(9): 1701-1732.

Kim, S., Schmitt, B., and Thalmann, N. (2019), Eliza in the uncanny valley: Anthropomorphizing consumer robots increases their perceived warmth but decreases liking, Marketing Letters, 30, 1-12.

Kitano, N. (2006), Rinri: An incitement towards the existence of robots in Japanese society, Ethics in Robotics, 6(12), Accessed: http://citeseerx.ist.psu.edu/viewdoc/download?doi=10.1.1.115.9957\&rep=rep1\&type=pdf\#page=80.

Kohler, T., Fueller, J., Stieger, D., and Matzler, K. (2011), Avatar-based innovation: Consequences of the virtual cocreation experience, Computers in Human Behavior, 27(1): 160-168.

Kowalski, R., Limber, S., and Agatston, P. (2012), Cyberbullying: Bullying in the Digital Age, Blackwell.

Kristensson, P., Matthing, J., and Johansson, N. (2008), Key strategies for the successful involvement of customers in the co-creation of new technology-based services, International Journal of Service Industry Management, 19(4): 474-491.

Kull, A. and Heath, T. (2016), You decide, we donate: Strengthening consumer-brand relationships through digitally cocreated social responsibility, International Journal of Research in Marketing, 33: 78-92.

Kumar, V., Dixit, A., Javalgi, R. and Dass, M. (2016). Research framework, strategies, and applications of intelligent agent technologies (IATs) in marketing. Journal of the Academy of Marketing Science, 44(1): 24-45. 
Larivière, B., Bowen, D., Andreassen, T., Kunz, W., Sirianni, N., Voss, C., Wünderlich, N., and De Keyser, A. (2017), Service encounter 2.0: An investigation into the roles of technology, employees, and customers, Journal of Business Research, 79(Oct): 238-246.

Leclercq, T., Hammedi, W., and Poncin, I. (2016), Ten years of value cocreation: An integrative review, Recherche et Applications en Marketing, 31(3): 26-60.

Lee, S., Olson, D. and Trimi, S. (2012), Co-innovation: Convergonomics, collaboration, and co-creation for organizational values, Management Decision, 50(5): 817-831.

Lee, S. and Sathikh, P. (2013), A framework for effective human-to-machine communication for artificial intelligence systems, $19^{\text {th }}$ International Conference on Engineering Design: Human Behavior in Design.

Leicht, T., Chtourou, A., and Youssef, K. (2018), Consumer innovativeness and intentioned autonomous car adoption, Journal of High Technology Management Research, 29(1): 1-11.

Lenka, S., Varida, V., and Wincent, J. (2017), Digitalization capabilities as enablers of value co-creation in servitizing firms, Psychology \& Marketing, 34(1): 92-100.

Li, L., Huang, Q., and Jian, Z. (2018), Human-computer interaction and value co-creation in electronic service, Industrial Management \& Data Systems, 118(1): 218-235.

Lombard, M. and Ditton, T. (1997), At the Heart of it all: The concept of presence, Journal of Computer-Mediated Communication, 3(2): Accessed (Jun 1, 2020) at: https://academic.oup.com/jcmc/article/3/2/JCMC321/4080403.

Lovelock, M. (2017), Catching a catfish: Constructing the 'good' social media user in reality television, Television \& New Media, 18(3), 203-217.

Luangrath, A., Peck, J., and Barger, V. (2017), Textual paralanguage and its implications for marketing communications, Journal of Consumer Psychology, 27(1): 98-107.

Lusch, R., Vargo, S., and O’Brien, M. (2007), Competing through service: Insights from service-dominant logic, Journal of Retailing, 83(1): 5-18.

Lv, Z., Jin, Y., and Huang, J. (2018), How do sellers use live chat to influence consumer purchase decision in China? Electronic Commerce Research and Applications, 28(Mar-Apr): 102-113.

MacInnis, D. (2011), A framework for conceptual contributions in marketing, Journal of Marketing, 75(Jul): 136-154.

Mahr, D., Lievens, A. and Blazevic, V. (2014), The value of customer cocreated knowledge during the innovation process, Journal of Product Innovation Management, 31(3): 599-615.

Marin, L., Issartel, J. and Chaminade, T. (2009), Interpersonal motor coordination: From human-human to human-robot interactions, Interaction Studies, 10(3): 479-504.

Marr, B. (2018). Artificial intelligence in business. Accessed (May 3, 2020) at: https://www.bernardmarr.com/default.asp?contentID=1314.

Maslow, A. (1954), Motivation and Personality, Harper \& Row.

McColl-Kennedy, J., Vargo, S., Dagger, T., Sweeney, J., and Van Kasteren, Y. (2012), Health care customer value cocreation practice styles, Journal of Service Research, 15: 370-389.

Mende, M., Scott, M., Van Doorn, J., Grewal, D., and Shanks, I. (2019), Service robots rising: How humanoid robots influence service experiences and elicit compensatory consumer responses, Journal of Marketing Research, 56(4): 535-556.

Merz, M., Zarantonello, L., and Grappi, S. (2018), How valuable are your customers in the brand value co-creation process? The development of a customer co-creation value (CCCV) scale, Journal of Business Research, 82: 79.

Mossberg, L., Hanefors, M. and Hansen, A. (2014), Guide performance: Co-created experiences for tourist immersion, In: Prebensen, N., Chen, J. \& Uysal, M. (Eds.), Creating Experience Value in Tourism, 234-247.

Nakanishi, H., Kato, K., and Ishiguro, H. (2011), Zoom cameras and movable displays enhance social telepresence, CHI 11: Proceedings of the SIGCHI Conference on Human Factors in Computing Systems: 63-72.

Ng, I., Maull, R., and Smith, L. (2011), Embedding the new discipline of service science, In: Demirkan, H., Spohrer, J. and Krishna, V. (Eds.), Service Science, Springer, 13-36.

$\mathrm{Ng}$, I. and Wakenshaw, S. (2017), The Internet-of-Things: Review and research directions, International Journal of Research in Marketing, 34(1): 3-21.

Nicod, L. and Llosa, S. (2018), How should customers be trained in their role as coproducers? The influence of training and its characteristics on the benefits of coproduction, Recherche et Applications en Marketing, 33(4): 46-73.

Normann, R. and Ramírez, R. (1994), Designing Interactive Strategy, Wiley.

Novani, S. and Kijima, K. (2012), Value co-creation by customer-to-customer communication: Social media and face-toface for case of airline service selection, Journal of Service Science and Management, 5(1): 1-5.

Oertzen, A., Odekerken-Schröder, G., Brax, S., and Mager, B. (2018), Co-creating services: Conceptual clarification, forms and outcomes, Journal of Service Management, 29(4): 641-679.

Osei-Frimpong, K. and McLean, G. (2018), Examining online social brand engagement: A social presence theory perspective, Technological Forecasting and Social Change, 128(Mar): 10-21.

Pirrone, D., Andolina, S., Santangelo, A., Gentile, A., and Takizawa, M. (2012), Platforms for human-human interaction in large social events, IEEE Xplore, Accessed: https://ieeexplore.ieee.org/abstract/document/6363113. 
Plé, L. and Chumpitaz Cáceres, R. (2010), Not always co-creation: Introducing interactional co-destruction of value in service-dominant logic, Journal of Services Marketing, 24(6): 430-437.

Pradeep, A., Appel, A., and Sthanunathan, S. (2019), AI for Marketing and Product Innovation, Wiley.

Prahalad, C. and Krishnan, M. (2008), The New Age of Innovation, McGraw-Hill.

Prahalad, C. and Ramaswamy, V. (2000), Co-opting customer competence, Harvard Business Review, 78(1): 79-90.

Prahalad, C. and Ramaswamy, V. (2004), Co-creation experiences: The next practice in value creation, Journal of Interactive Marketing, 18(3): 5-14.

Raïes, K. and Gavard-Perret, M.L. (2011), Brand loyalty intention among members of a virtual brand community: The dual role of commitment, Recherche et Applications en Marketing, 26(3): 23-41.

Ramaswamy, V. and Ozcan, K. (2016), Brand value co-creation in a digitalized world: An integrative framework and research implications, International Journal of Research in Marketing, 33(1): 93-106.

Ramaswamy, V. and Ozcan, K. (2018), What is co-creation? An interactional creation framework and its implications for value creation, Journal of Business Research, 84: 196-205.

Ranjan, K. and Read, S. (2016), Value co-creation: Concept and measurement, Journal of the Academy of Marketing Science, 44(3): 290-315.

Rice, R. (1993), Media appropriateness: Using social presence theory to compare traditional and new organizational media, Human Communication Research, 19(4): 451-484.

Saha, V., Hollebeek, L., Venkatesh, M., and Goyal, P. (2020), Value cocreation, Working Paper.

Schau, H., Muniz, A. and Arnould, E. (2009), How brand community practices create value, Journal of Marketing, 73(5): $30-51$.

Short, J., Williams, E., and Christie, B. (1976), The Social Psychology of Telecommunications. London: John Wiley.

Song, J.H. and Hollenbeck, C. (2015), The value of social presence in mobile communications, Service Industries Journal, 35(11-12), 611-632.

Song, J.H., Hollenbeck, C., and Zinkhan, G. (2008), The value of human warmth: Social presence cues and computermediated communications, In: Lee, A. and Soman, D. (Eds.), North American Advances in Consumer Research, 35, 793-794.

Schweitzer, F., Belk, R., Jordan, W., and Ortner, M. (2019), Servant, friend or master? The relationships users build with voice-controlled smart devices, Journal of Marketing Management, 35(7/8): 693-715.

Smedlund, A. (2012), Value cocreation in service platform business models. Service Science, 4(1): 78-88.

Smedlund, A. and Faghankhani, H. (2015), Platform orchestration for efficiency, development, and innovation, $48^{\text {th }}$ Hawaii International Conference on Systems Science, Accessed (May 7, 2020) at: https://ieeexplore.ieee.org/xpl/conhome/7068092/proceeding.

Smith, A. (2013), The value co-destruction process: A customer resource perspective, European Journal of Marketing, 47(11-12): 1889-1909.

Täuscher, K. and Laudien, S. (2017), Understanding platform business models: A mixed methods study of marketplaces, European Management Journal, 36(3): 319-329.

Tixier, M., Lewkowicz, M., Maroccia, M., Atifi, H., Bénel, A., Gaglio, G., and Gauducheau, N. (2010), Practices analysis and digital platform design: An interdisciplinary study of social support, COOP2010, 309-329.

Troisi, O., D'Arco, M., Loia, F., and Maione, G. (2018), Big data management: The case of Mulino Bianco's engagement platform for value co-creation. International Journal of Engineering Business Management, DOI: https://doi.org/10.1177/1847979018767776.

Tu, C. (2000), On-line learning migration: From social learning theory to social presence theory in a CMC environment, Journal of Network and Computer Applications, 23(1): 27-37.

$\mathrm{Tu}$, J. and Zhang, M. (2013), Research on the effect of co-creation customer experience on customer co-created value in non-trading virtual community, IEEE International Conference on Service Operations and Logistics, Accessed (Jun 24, 2020) at: https://ieeexplore.ieee.org/abstract/document/6611395.

Uhrich, S. (2014), Exploring customer-to-customer value cocreation platforms and practices in team sports, European Sports Management Quarterly, 14(1): 25-49.

Van Doorn, J., Mende, M., Noble, S., Hulland, J., et al. (2017), Domo arigato Mr. Roboto: Emergence of automated social presence in organizational frontlines and customers' service experiences, Journal of Service Research, $20(1): 43$.

Vanhouette, E. (2016). The gates of hell: History and definition of digital | humanities | computing. In: Terras, M., Nyhan, J. \& Vanhouette, E. (Eds.), Defining Digital Humanities, 119-156, Taylor \& Francis.

Vargo, S. and Lusch, R. (2004), Evolving to a new dominant logic for marketing, Journal of Marketing, 68(1): 1-17.

Vargo, S. and Lusch, R. (2008), Service-dominant logic: Continuing the evolution, Journal of the Academy of Marketing Science, 36(1): 1-10.

Vargo, S. and Lusch, R. (2010), From repeat patronage to value co-creation in service ecosystems: A transcending conceptualization of relationship. Journal of Business Market Management, 4: 169-179.

Vargo, S. and Lusch, R. (2016), Institutions and axioms: An extension and update of service-dominant logic, Journal of the Academy of Marketing Science, 44(1): 5-23. 
Vega-Vazquez, M., Revilla-Camacho, A., and Cossio-Silva, J. (2013), The value co-creation process as a determinant of customer satisfaction, Management Decision, 51(10): 1945-1953.

Verma, R., Gustafsson, A., and Witell, L. (2012), Customer co-creation in service innovation: A matter of communication? Journal of Service Management, 23(3): 311-327.

Voss, K., Spangenberg, E., and Grohmann, B. (2003), Exploring the hedonic and utilitarian dimensions of consumer attitude, Journal of Marketing Research, 40(3): 310-320.

Weyerer, J. and Langerer, P. (2019), Garbage in, garbage out: The vicious cycle of AI-based discrimination in the public sector, Proceedings of the 20th Annual International Conference on Digital Government Research, 509-511.

Wiener, M. and Mehrabian, A. (1968), Language within Language: Immediacy, a Channel in Verbal Communication, Ardent Media.

Willcocks, L., Lacity, M., and Craig, A. (2015), Robotic process automation at Xchanging, The Outsourcing Unit Working Paper Series, Accessed (May 1, 2020) at: http://eprints.lse.ac.uk/64518/1/OUWRPS_15_03_published.pdf.

Wirtz, J., Patterson, P., Kunz, W., Gruber, T., Lu, V., Paluch, S., and Martins, A. (2018), Brave new world: Service robots in the frontline, Journal of Service Management, 29(5): 907-931.

Witell, L., Kristensson, P., Gustafsson, A. and Lofgren, M. (2011), Idea generation: Customer co-creation versus traditional market research techniques, Journal of Service Management, 22(2): 140-159.

Woodruff, R. (1997), Customer value: The next source for competitive advantage, Journal of the Academy of Marketing Science, 25(2): 139-153.

Wu, Y., Wu, C., Li, B., Zhang, L., Li, Z., and Lau, F. (2014), Scaling social media applications into geo-distributed clouds, IEEE/ACM Transactions on Networking, Accessed (Jun 22, 2020) at: https://core.ac.uk/download/pdf/38052757.pdf.

Wünderlich, N., Wangenheim, F., and Bitner, M.J. (2013), High tech and high touch: A framework for understanding user attitudes and behaviors related to smart interactive services. Journal of Service Research, 16(1): 3-20.

Yadav, M. (2010), The decline of conceptual articles and implications for knowledge development, Journal of Marketing, 74(1): 1-19.

Zeithaml, V. (1988), Consumer perceptions of price, quality, and value: A means-end model and synthesis of evidence, Journal of Marketing, 52(Jul): 2-22.

Zhang, T., Lu, C., Torres, E., and Chen, P. (2018), Engaging customers in value co-creation or co-destruction online, Journal of Services Marketing, 32(1): 57-69. 